\section{CHIVA 30 years later. Scientific and ethical considerations}

\section{Claude Franceschi \\ Centre de soins Marie Thérèse, Paris, France}

In the seventies and eighties, we had more and more patients who needed a saphenous vein by-pass due to the fact that the previous one was unfortunately destroyed by a surgical or endo-venous treatment. I was struck by our schizophrenic behavior which consisted of, on the one hand, the saphenous vein destruction for the benign varicose disease and on the other hand, lamenting for its absence when we needed it to perform a venous by-pass for a critical or life-threatening arterial or coronary obstruction. So, as a former psychiatrist, I decide to confront and treat my insanity. In addition to conservative treatments as foot elevation, bandaging and compressive stocking, I tried to find a surgical treatment which could also preserve the saphenous capital. My observations of the varicose veins disappearance when I lifted the feet of my patients combined together with the Trendelenburg and Perthes maneuvers effects, convinced me that the cause of the venous insufficiency and its symptoms as the varicosity was just a hemodynamic impairment of the venous flows and pressure control. ${ }^{1-10}$ Then, on these grounds and thanks to the studies of the venous pressure mainly published by Bjordal and the revolutionary capability of recent EchoDoppler Ultrasound devices, I could figure out a better hemodynamics of the venous system and its anomalies. From all this, new proposals of venous pathophysiological hemodynamic principles resulted, as the Dynamic Fractioning of Hydrostatic pressure, various Venous Shunt patterns, Re-entry concept, Trans-mural Pressure control as the target of any rational treatment, location of not yet individualized pelvic leak points, hemodynamic venous cartography, and finally the necessary conservation of the venous network for a correct drainage of the tissues and prevention of recurrence. These concepts were the basis of the CHIVA treatment (French acronym for cure Conservatrice Hémodynamique de l'Insuffisance Veineuse en Ambulatoire) published in 1988. As Conservation is a pillar, CHIVA was received as provocative nonsense because, so far, the destructive paradigm was dominant. Indeed, for almost a century, research, studies and devices where focused on killing the veins because the treatment failures and recurrences where attributed to the veins left behind. Indeed, CHIVA is based on a dramatically different pathophysiological rational. Its concepts were ver- ified by further experimental evidence. Thanks to hundreds of studies, some RCTs and a Cochrane review, achieved by various authors over Europe, CHIVA is today validated as more successful than destructive method and reaches at the same time, both targets of treating efficiently the venous insufficiency and preserving the venous capital for future by-pass. ${ }^{11-13}$

CHIVA is also a scientific and intellectual challenge, which demands a reconsideration of the mainstream knowledge and personal habits, a steep learning curve of the appropriate venous hemodynamics and its related Duplex Scan assessment. We cannot play a game of chess with the rules for checkers even if the board is quite identical (10 vs 8 squares). The same is for CHIVA. The rules of destructive methods cannot fit the conservative CHIVA. Conservative or ablative methods, as well as invasive and non-invasive or laser and other advanced devices, are powerful marketing topics but not always medically fair. The Conservative procedures are relevant only when they are better than the ablative ones in terms of risks/benefits ratio. Non-invasive procedures are not necessarily safe. CHIVA is feasible in outpatients with mini-invasive surgery. ${ }^{8-10}$

The patient information should point out the risks/benefits based on the medical evidence. That is like kicking down an open door if we refer to the Hippocratic Oath: ' $I$ follow that system of regimen which, according to my ability and judgment, I consider for the benefit of my patients, and abstain from whatever is deleterious and mischievous.' Furthermore, the patient Informed Consent obliges to inform the patient about the nature and purpose, risks and benefits of the proposed treatment as well as the alternatives.

Unfortunately, reality is not so good. Ignorance, cynicism, competition, greed and conflicts of interest shall still be taken into account.

I would like to revive the fair Hippocratic Oath by permitting the phlebologist to better inform and treat the patient. Remind him that varicose veins are usually benign and may be treated or not according to his/her cosmetic or comfort expectation. In case of skin changes and ulcers, easy efficient procedures on transmural pressure decrease are available. In addition, the CHIVA concepts and strategy are applicable to the deep venous diseases, particularly post-thrombotic, and also to the venous malformations.

\section{References}

1. Carandina S. Varicose vein stripping vs haemodynamic correction (CHIVA): a long term randomised trial. Eur J Vasc
Correspondence: Claude Franceschi, Centre de soins Marie Thérèse, Paris, France. E-mail: claude.franceschi@gmail.com

Key words: Patients-phlebologists relationship; questions; Italian Association of Phlebology seminar.

This work is licensed under a Creative Commons Attribution 4.0 License (by-nc 4.0).

(C) Copyright C. Franceschi, 2019

Licensee PAGEPress, Italy

Veins and Lymphatics 2019; 8:8229

doi:10.4081/vl.2019.8229

Endovasc Surg 2008;35:230-7.

2. Parés JO. Varicose vein surgery: stripping versus the CHIVA Method: a randomized controlled trial. Ann Surg 2010;251:62431.

3. Iborra-Ortega E. Comparative study oftwo surgical techniques in the treatment of varicose veins of the lower extremities: results after five years of follow up. Angiología 2006;58:459-68.

4. Chan C-Y. Retrospective comparison of clinical outcomes between endovenous laser and saphenous vein-sparing surgery for treatment of varicose veins. World J Surg 2011;35:1679-86.

5. Wang H. Hemodynamic classification and CHIVA treatment of varicose veins in lower extremities (VVLE). Int J Clin Exp Med 2016;9:2465-71.

6. Malgor RD. Morbidity and mortality after thermal venous ablations. Int Angiol 2016;35:57-61.

7. Zamboni P. Minimally invasive surgical management of primary venous ulcers vs. compression treatment: a randomized clinical trial A. EJ V E S 2003.

8. Franceschi C, Zamboni P. Principles of venous haemodinamics. New York, NY: Nova Science; 2008.

9. Franceschi C, Ermini S. The evaluation of essential elements defining varicose vein mapping. Veins and Lymphatics 2014;3:4922.

10. Zamboni $\mathrm{P}$, Spath $\mathrm{P}$, Tisato $\mathrm{V}$, et al Oscillatory flow suppression improves inflammation in chronic venous disease. J Surg Res 2016;205:238-45.

11. Romiti M. Meta-analysis of infrapopliteal angioplasty for chronic critical limb ischemia. J Vasc Surg 2008;47:975-81.

12. Papakonstantinou NA. No touch technique of saphenous vein harvesting: Is great graft patency rate provided? J Thorac Cardiovasc Surg 2015;150:880-8.

13. Ziza V. Outcomes of cold-stored venous allograft for below-knee bypasses in patients with critical limb ischemia. J Vasc Surg 2015;62:974-83. 